\title{
Patterns, Consequences, and Possible Causes of Dropout in Upper Secondary Education in Mexico
}

\author{
Raja Bentaouet Kattan ${ }^{1}$ and Miguel Székely ${ }^{2}$ \\ ${ }^{1}$ The World Bank, 1818 H Street NW, Washington, DC 20433, USA \\ ${ }^{2}$ Center for Education and Social Studies, Insurgentes Sur 2375, Delegación Álvaro Obregón, 01090 Mexico City, DF, Mexico \\ Correspondence should be addressed to Miguel Székely; mszekely@prodigy.net.mx
}

Received 19 September 2014; Revised 23 January 2015; Accepted 23 January 2015

Academic Editor: Gwo-Jen Hwang

Copyright ( 2015 R. Bentaouet Kattan and M. Székely. This is an open access article distributed under the Creative Commons Attribution License, which permits unrestricted use, distribution, and reproduction in any medium, provided the original work is properly cited.

\begin{abstract}
The present study provides a detailed analysis of upper secondary education dropout patterns in Mexico, exploring its consequences and possible causes. To perform the analysis we combine different databases and statistical methods ranging from the use of surveys with information on specific individuals to data aggregated at the municipal and state level. The main value added is the simultaneous analysis of the influence of individual-family, community, and macroaggregate factors, on school dropout in the country.
\end{abstract}

\section{Introduction}

Recent studies by the Organization for Economic Cooperation and Development (OECD [1]) show that Mexico is one of the countries with the greatest growth potential to be gained from improvements in its education. Despite this, lagging educational attainment and education quality have hindered Mexico's ability to realize that potential.

One of the biggest roadblocks faced by the country to accelerate educational improvement is found at the upper secondary level. In 2012, basic education coverage rates in Mexico exceeded 95 percent, a level similar to the observed even in developed countries. However, in the case of upper secondary education (USE), Mexico remains a country with low coverage and achievement rates; the current USE graduation rate in Mexico is 47 percent compared with an average of 84 percent in other OECD countries (OECD (2012) (http://www.oecd-ilibrary.org/education/data/educationdatabase_edu-db-data-en;jsessionid=29ffffow20wf0.x-oecdlive-03)). Even when compared to the Latin American average of 52 percent, the USE completion rate in Mexico is considerably lower: while only 37.5 percent of the population aged 25 to 29 has completed USE in Mexico, the completion rate for the region is considerably higher at 48 percent.
The difference is also stark for older cohorts, with the USE completion rate for those aged 30 to 34 years standing at 32 percent while the regional average is 42.6 percent (Regional Monitoring Report on Progress Toward Quality Education for All in Latin America and the Caribbean, EFA 2012, UNESCO, Paris, France).

The dropout situation is particularly concerning because, in addition to dropout's negative effects on the productivity of human resources, the official age for attending USE in Mexico between 15 and 18 years of age is also a critical time in the life cycle for an individual's development. Given the pressing challenge and importance of USE today addressing dropout at the upper secondary level is therefore a critical issue.

The present study provides a detailed analysis of USE dropout patterns in Mexico, exploring its patterns, consequences, and possible causes. Previous studies of USE in Mexico have focused primarily on the analysis of educational provision and its contents (including Castañón and Seco [2], Didou and Martínez [3], Zorrilla [4], and Zorrilla et al. [5]), and there are also several historical analyses of the evolution of the sector, including Solana et al. [6] and Arredondo [7]. Unlike these studies, the present analysis focuses on the problem of school dropouts in the USE level, and to our 
knowledge, it is the first that addresses this problem by using the most current information.

The document is organized into four sections. The first presents evidence, both historical and recent, of USE dropout patterns. The second lays out new information on the current consequences of dropping out for youth in the academic, economic, and social spheres. The third section uses different data and statistical techniques to investigate the possible causes behind dropout in USE, including personal and family factors, social and community, and general or macro factors. The fifth section concludes.

\section{School Dropout Patterns in Mexico}

Mexico has made significant progress in increasing educational gross coverage in recent decades. According to official statistics from SEP [8], the primary gross enrollment rate has surpassed 98 percent since the early 1990s, while in the case of secondary, a substantial expansion was observed from 66 to 93 percent in two decades. In the case of USE, a significant expansion was also observed with coverage almost doubling in the span of 20 years, reaching 66 percent in 2012. Similarly in higher education, coverage more than doubled in the same period.

In USE, a similar trend has been observed in net coverage rate rates. The result obtained from processing the National Household Income and Expenditure Survey (ENIGH) developed by the National Institute of Statistics and Geography (INEGI) shows that in 1984, 28 per cent of the population between 15 and 18 years old attended USE, 18 percent were attending secondary education, which is a lower level than expected for their age, and about 4 percent were still in primary education. Since then, a continuous increase has been observed in the proportion of people in this age group that attends USE, reaching 59 percent in 2012.

The increase in coverage in USE is attributable to three main factors. The first is the expansion in supply of services at this level. The second is the increase in the coverage of secondary education, which implies that a higher percentage of individuals in each cohort have the academic requirements to enter USE. The third is that a higher percentage of graduates of secondary education access USE upon completion of secondary. According to SEP [8] absorption of primary graduates to secondary schooling increased from 75 to 95 percent, while for USE the observed increase in absorption was from 83 to 95 percent during the same period, an increase by 14 percent. Also noteworthy is the increase from 70 to 80 percent in absorption in higher education.

Despite these advances, Mexico's education system has the largest dropout rates at the upper secondary level, which is the focus of this analysis. Figure 1 presents the evolution of dropout rates by education level between 1990 and 2012 and shows that historically rates in USE have almost doubled those recorded in other levels. In the span of 20 years, dropout has virtually disappeared at the primary level; it has been reduced by 66 percent in Secondary but has only fallen by 4.3 percentage points in USE. In 2012, a USE dropout rate of 14.5 percent per year was recorded, which means that in

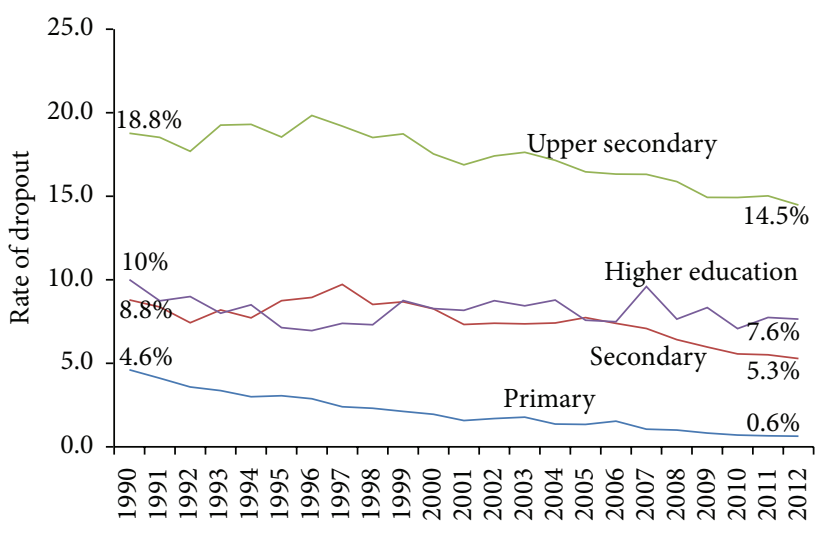

FIGURE 1: Evolution of the rate of dropout by education level in Mexico 1990-2012. Source: author's calculations from SEP [8].

the course of the three years covered by this level nearly 45 percent of original entrants dropped out.

Figure 2 shows the implications of these trends by following the path of a typical cohort advancing through the educational system, taking into account the coverage, absorption and dropout rates from each of the levels of the educational chain. Using data from the Ministry of Public Education (SEP) [8], for 2012 the cycle starts with virtually 100 percent of children of primary school age enrolled in this level. However, during the 6 years of this cycle 4 percent drop out, and 96 percent complete. That is, for every 100 children who enroll, 96 finish the first 6 years of study. The rate of absorption into secondary education is 97 percent, which means that of the 96 students that completed, almost 93 continue. Of these, 84.5 percent culminate in secondary, resulting in the retention of 78.7 out of 100 original students. The rate of absorption into USE is 91.6 percent (i.e., of the 78.7 continuing students, around 72 are enrolled). However, high dropout rates in USE have resulted in only 45.6 of the original students completing this level. Finally about 85 percent of those who completed USE entered higher education, which means that for every 100 students entering at the start of primary education only 39 remain in the educational system to enter higher education. The rate of terminal efficiency in higher education is 71 percent nationally, meaning that only 27 of the original 100 students who entered primary education manage to get their degree.

Figure 2 also compares the dynamics observed 20 years earlier, in 1990. During that year, the reduction in the population throughout the educational system was even greater. Out of 100 students who entered primary education, only 13.6 reached higher education. The difference is that the rates of absorption and retention throughout the entire cycle were lower. In primary, instead of 95 out of 100 completing on average, only $70 \mathrm{did}$, and the rate of absorption to secondary education was 15 points lower. Only 83 percent of those who entered secondary education completed that level, and 75 percent of them accessed USE.

One of the most notable phenomena, which factors into this analysis, is that in 1990, between the point of entry to USE and graduation, almost 16 of each 100 who had entered primary dropped out, while in 2012, 26.5 of every 100 original 


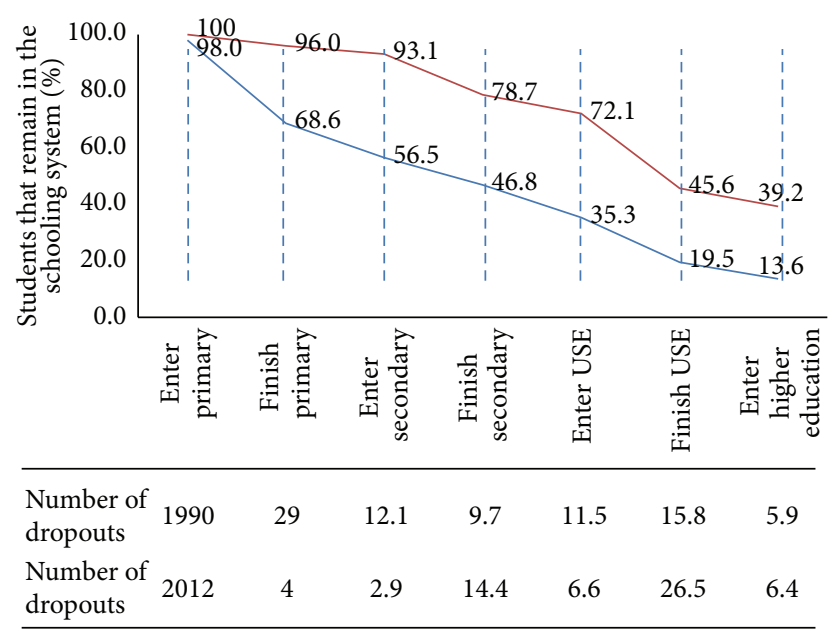

FIGURE 2: Average school trajectory from primary to higher education in Mexico in 1990 and 2012. Source: author's calculations from SEP [8].

students left school during the same transition (see table in the lower section of Figure 2). This is due, on one hand, to a greater number of students gaining access to USE as a result of increased secondary education completion rates as discussed above, but also the data clearly shows that USE did not evolve at the same rate and in that sense has become a bottleneck for the national education system.

\section{The Consequences of Upper Secondary Dropout}

Dropout from USE has a wide range of consequences. The most direct is that since the learning process is cumulative, noncompletion of this level prevents transition to the next (higher education, HE). Even at the national level, according to the official data from SEP [8], the rate of absorption of $\mathrm{HE}$ is 85 percent nationally. Therefore, it can be argued that satisfactorily completing USE in Mexico is accompanied by a high probability of access to higher education.

In addition dropout from USE affects a youth's ability to access better economic opportunities, since HE generates higher returns in the labor market. To verify the level of the spreads between returns, we estimate the returns to different educational levels using data from the National Employment Survey (ENE) from INEGI for the third quarter of 2013 for all individuals aged 19 to 45 who receive an income from employment (including the formal and informal sectors). This source includes information for all participants in economic activity as well as their level of education (we estimate the returns individually by a traditional Mincer equation for individuals who report labor income and correct for selection bias. The result of the selection bias correction model is presented in Appendix Table A1 in the Supplementary Material available online at http://dx.doi.org/10.1155/2015/676472, where it can be seen that the $\lambda$ coefficient is significant).

According to the estimations, having HE is associated with income levels about 3.5 times greater than those observed for individuals who have only secondary education and twice than those who completed only (at best) USE. Additionally the estimation shows that on average, the income of an individual who completes USE is 61.5 percent greater than his or her counterpart who dropped out prematurely from this level.

To provide an overview of the most immediate consequences of dropping out before completing USE we explore data from the National Survey of Educational and Labor Trajectories of higher Secondary Education (ENILEMS) from 2010 and 2012. Both surveys are specifically designed to study the working conditions of different populations, so the data can provide insight into the consequences of not completing USE.

According to our estimates, the employment rate of those who did not complete USE was 45 percent, while among those who did complete USE the rate was of 60 percent. Another distinct pattern was identified in terms of the types of employment observed. According to our results, only 37 percent of employed individuals who did not complete USE are employed in the formal sector, while among those who did complete USE the share is almost 50 percent. This difference suggests that completion of USE is associated not only with employment but also with employment in better conditions (to explore in more detail the effect of finishing and graduating from USE compared to not having completed this level, we estimate a series of Probit models including as independent control variables household characteristics, income, characteristics of the head, spouse characteristics, asset values, etc. We estimate a traditional regression of logarithm of income as a function of those variables and include dummy variables indicating USE completion and find that finishing USE is positively and significantly associated with the odds of finding a job and finding employment (of 7 percent in both cases) and of obtaining a higher income in the labor market equivalent to 17 percent).

As for the social consequences of school dropout before the typical age of USE completion the National Youth Survey (ENJ) 2010 includes information on sexual behavior, alcohol consumption, drug use, and other behaviors, in youth, which can be associated with schooling patterns (The National Youth Survey was implemented in 2005 and 2010, resp., and in both cases it was applied to a representative number of households on the condition that there was at least one young person (12 to 29 years old). In these households a youth was chosen to answer an expanded questionnaire (with information on dropouts, and social issues related to sexuality, violence, and addiction) while other household members were given a basic module of sociodemographic characteristics. The survey has coverage at national, regional, and state/municipal levels and for metropolitan areas. The USE dropout level estimated from it is 11 percent per year, which is lower than the 14 percent recorded by official statistics discussed in Section 2 of this document. Given the characteristics of the sample it is likely that the discrepancy is due to subdeclaration of dropout rates given by the fact that some youths who are outside the education system cannot be seen as deserters by having the intention to return in the future). 
In order to explore associations between these types of high risk behaviors and dropout from the education system, we estimated a series of Probit regressions where the dependent variable was the risk behavior or practice under analysis in each case, for youth aged 19 to 24 . As independent variables we consider economic status and household structure-both of which are generally identified as important determinants of social risks-as well as a variable indicating whether the individual in question dropped out of the education system before completing USE and before reaching age 18 .

It is important to note that the survey includes information on self-reported behaviors, which tend to be underreported, likely leading to underestimation of the magnitude of the true association between dropout and the risk being studied. Further, although we provide estimates for youth who have transcended the age of USE, there is likely to be endogeneity between variables, as dropout during the age of USE (15 to 18 ) may have been caused by the proclivity to begin engaging in risky behaviors which are included in the estimates as independent variables. To address this issue, at least to some extent, we include as control variable a "risk incidence index" constructed from the data in the 2005 ENJ (which is comparable to the 2010 survey) for individuals of 13 to 18 years of age. These individuals belong to the same cohort represented by those observed five years later in 2010 at ages 19 to 24 (to compute the risk incidence index we classify the population of 13-18 years of age in 2005 simultaneously by rural/urban location, gender, education of the household head, education of the spouse of the household head, belonging to an indigenous group, absent parent, and employment of the household head. For each cell specified according to these variables we calculate the risk incidence index as the average of the share of individuals that declare suffering violence in couples, having been forced to have sex, being pregnant before age 18, smoking cigarettes, drinking alcohol, and consuming drugs regularly, resp. The average is obtained for $13,14,15,16,17$, and 18 year olds in the 2005 survey. The value of the cell means is then linked to individuals in the 2010 survey that are 19, 20, 21, 22, 23, and 24 years of age, resp. Thus, for instance, for individuals aged 19 in 2010, we link the risk incidence index for 14 year olds in 2005 for the cell that corresponds to the individual's urban/rural location, gender, education of the household head, education of the spouse, and so on. It must be noted that the average value of this indicator is small in most cells. This is perhaps the reason why it is not statistically significant in the estimated regressions. Furthermore, the sign and magnitude of the coefficients remain very similar when excluding this variable from the regression (the results of estimating the equation without this control variable are presented in a previous version of the paper)). However, our estimates should still be interpreted as associations and correlations, and not fully as causal relations, since it is possible that the index of risk behavior for the same cohort observed 5 years before in 2005, used as control, might have also underreported such information.

Table 1 presents the results for 6 estimations. In all cases, the first independent variable is a dummy variable that takes the value 1 when the individual in question left the education system before completing USE (the middle regression where teen pregnancy is used as dependent variable is only estimated for females). We then incorporate a set of personal variables including gender, age, and marital status, followed by access to scholarships and medical services, household characteristics and assets, the features of the head of household, and the risk incidence index observed five years before.

In the first two estimations the dependent variables attempt to capture information on the stability in interpersonal relationships to inquire whether the individual in question has suffered partner violence or has been forced to engage in sexual activity. In the second regression our estimates show a positive and significant association with dropout. The third estimate verifies the relationship between teen pregnancy or parenthood before age 18 and dropout before completing USE. In this case also a positive and significant relation is found. However, it is this latter model where potential endogeneity may exist to a larger extent, as described above.

The following three estimates refer to different types of addictions observed among youths between the ages of 19 and 24 years, including information on the frequent use of cigarettes, alcohol, and drugs. In all cases the coefficient for USE dropout is positive and statistically significant suggesting that there is an association between the prevalence of addictions and dropping out of the education system prematurely before completing the USE level.

\section{School Dropout and Associated Factors}

There is an extensive body of literature on the causes of dropout in the context of the risks that youth face. In general, three broad types of factors associated with this condition are observed: personal-family, social-community, and macro or general (see, e.g., Cunningham et al. [9]).

The first of these refers to the set of personal and family characteristics that determine individual behavior. These range from biological characteristics such as gender, race, or ethnicity, to cognitive abilities, personality, psychological, and behavioral characteristics. Family factors relate to personal interactions with other family members, those who live inside or outside the home, and to the resources available to the family unit.

On the other hand, social-community factors have to do with the quality of education services, health, protection, infrastructure, and security, which determine the context in which people operate, as well as the influence of the environment and social groups within it. The inadequacy or lack of services, including the quality of education, is a risk factor in itself and can also be triggered from exposure to other vulnerabilities.

The third group of factors (macro or general) relates to the context and the institutions that affect individuals. However, unlike in the personal-family and the social-community groups of factors, these include those that generally cannot be affected or modified by individual behavior and are taken as external. 
TABLE 1: Association between risk behavior and dropout in youth aged 19 to 24 years in Mexico, 2010.

\begin{tabular}{|c|c|c|c|c|c|c|}
\hline \multirow[b]{2}{*}{ Independent variable } & \multicolumn{6}{|c|}{ Independent variable } \\
\hline & $\begin{array}{c}\text { Has suffered } \\
\text { violence in } \\
\text { couples }\end{array}$ & $\begin{array}{l}\text { Has been } \\
\text { forced to } \\
\text { have sex }\end{array}$ & $\begin{array}{l}\text { Got pregnant } \\
\text { before } 18 \text { years } \\
\text { of age }\end{array}$ & $\begin{array}{l}\text { Smokes } \\
\text { cigarettes } \\
\text { regularly }\end{array}$ & $\begin{array}{l}\text { Drinks } \\
\text { alcohol } \\
\text { regularly }\end{array}$ & $\begin{array}{c}\text { Consumes } \\
\text { drugs } \\
\text { regularly }\end{array}$ \\
\hline Dropped out before completing USE & -0.050 & $0.013^{*}$ & $0.053^{*}$ & $0.022^{*}$ & $0.026^{*}$ & $0.009^{* *}$ \\
\hline Age & 0.001 & 0.002 & $0.030^{* * *}$ & $0.006^{*}$ & $0.007^{* *}$ & -0.001 \\
\hline Sex & 0.002 & $-0.012^{* *}$ & $-0.124^{* * *}$ & $0.101^{* * *}$ & $0.134^{* * *}$ & $0.006^{* *}$ \\
\hline Married or cohabiting & -0.013 & 0.001 & $0.343^{* * *}$ & $-0.067^{*}$ & -0.034 & -0.004 \\
\hline Lives with partner & 0.000 & -0.000 & $0.438^{* * *}$ & $0.075^{* *}$ & 0.032 & 0.006 \\
\hline Medical service & 0.037 & -0.004 & $0.055^{* *}$ & $-0.034^{* *}$ & $-0.033^{* *}$ & $-0.006^{*}$ \\
\hline Oportunidades scholarship & 0.127 & 0.001 & -0.032 & 0.000 & -0.056 & 0.000 \\
\hline Size of household & 0.010 & -0.000 & $0.068^{* * *}$ & 0.000 & 0.000 & 0.000 \\
\hline Rural & -0.059 & $-0.012^{* *}$ & $-0.056^{* *}$ & -0.021 & -0.015 & -0.002 \\
\hline Index of assets & -0.014 & $-0.006^{* *}$ & $-0.035^{* * *}$ & $0.017^{* * *}$ & $0.029^{* * *}$ & 0.001 \\
\hline Education head of household & -0.008 & 0.001 & -0.002 & -0.000 & 0.009 & 0.000 \\
\hline Education of spouse & 0.005 & -0.000 & 0.000 & 0.0021 & -0.004 & -0.000 \\
\hline Head speaks indigenous language & -0.016 & -0.002 & $-0175^{* * *}$ & -0.037 & -0.044 & -0.007 \\
\hline Head is employed & 0.061 & -0.013 & 0.0101 & 0.008 & -0.008 & -0.000 \\
\hline Absent parent & 0.012 & 0.006 & $0.095^{* * *}$ & $0.029^{*}$ & 0.024 & 0.000 \\
\hline \multicolumn{7}{|l|}{ Risk incidence index observed } \\
\hline 5 years before in the ENJ 2005 & .0022 & .0034 & .0003 & .0005 & .0012 & .0023 \\
\hline
\end{tabular}

Source: own calculations. The estimates reported represent the average margins evaluated.

$*, * *$, and $* * *$ represent statistical significance at $10 \%, 5 \%$, and $1 \%$, respectively.

The importance of these groups of factors is confirmed by the self-reported data in the National Survey of Dropout in Upper Secondary Education (ENDEMS) in Mexico for 2011. According to the survey, which was applied to a nationally representative sample of 13,014 youth between ages 14 to 25 that had dropped out from school during USE, for 36.4 percent of respondents the main cause of dropout was the lack of financial resources to cover the expenses of attending school. For 29.5 percent the main cause for dropping out was related to academic and school issues, including difficulties understanding the teachers, dislike of studying, failing subjects, and assignment to a different shift than desired. Finally, the third main cause was related to personal causes, with 23.1 percent. Personal causes included pregnancy, considering that work was more important than staying in school, or quitting school to get married.

The self-reported causes of dropout that emerge from the National Youth Survey (ENJ) 2010 confirm the relevance of these factors, although with somewhat different weight. According to the ENJ the leading category of causes of dropout (reported among 42.6 percent) of youth aged 15 to 18 is educational factors. Among this group 15.9 percent of youth declare leaving because they were bored, 13.1 declare that they did not want to continue their studies because school was not relevant, while 9.6 percent mentioned that they left school because of repetition or being over age. The second most common grouping of causes for dropping out is related to economic factors. Among 35.5 percent of youth surveyed, the main reason for dropping out included having to work, lack of money, or being unable to pay for school. The third grouping refers to personal circumstances (including marriage/union and paternity/maternity), which combined account for about 8 percent. Finally, the fourth group of causes (with 7.5 percent of all mentions) includes aspects that have to do with the educational supply and the lack or difficulty of access to educational services.

In what follows we attempt identifying the importance of some of these elements through statistical relationships.

4.1. Personal, Family, and Economic Factors. In order to explore the importance of personal, family, and economic factors with respect to dropout we estimate a Probit model using household data of each youth of USE age from the ENIGH survey. The estimation corresponds to the marginal effect of each feature on the likelihood of having dropped out of USE. As a first step we estimate a basic model using existing ENIGH data between 1984 and 2012, which contain a relatively limited number of comparative and available variables in each survey but allow obtaining an overview of the importance of various elements over almost three decades. Figure 3 presents the results and shows that there are significant changes over the years-we include only variables that consistently show a statistically significant effect (because of the potential problems of multicollinearity and endogeneity among variables, the marginal effects should be taken only as patterns of association without necessarily having a relationship of strict causality). 


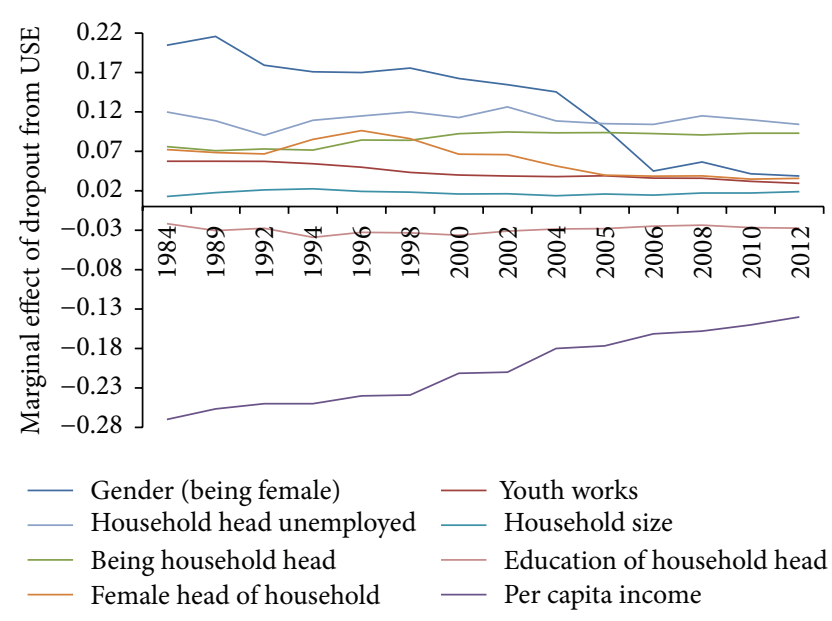

FIGURE 3: Estimated probability of dropout from USE associated with personal and family characteristics 1984-2012. Source: authors calculations based on data from ENIGh 1984-2012.

In the early 1980s the characteristic most strongly associated with dropout was female gender, which increased the probability of dropping out of the education system at the age of USE by more than 20 percent. However, there is a declining trend in the value of this coefficient between 1989 and 2004, with a steep reduction during 2004-2006 and the persistence of considerable lower levels thereafter, to the extent that in 2012 being female was associated with a 5 percent higher probability of dropping out. This result is consistent with the reversal in the gender gap in USE attendance observed in Mexico during the past 30 years. According to our calculations from ENIGH data in 1984, 38 percent of 15-18-year-old males attended USE while only 27 percent of females in the same age bracket did so. In contrast, in 2012, 56 percent of 15-18 males attended USE, while 59 percent of females of the same age attended this level. Interestingly, the reversal in the gender gap in USE attendance rates occurs precisely in 2002, after which the influence of gender on school dropout declines significantly.

The result may be due to multiple factors. For instance, according to Fiszbein and Schady [10] education gender gaps closed or reversed in Mexico and other Latin American countries mainly as consequence of the implementation of conditional cash transfer programs; these programs provide cash transfers of higher value for females attending school than for males, and different impact evaluations show that the effects of school attendance for females are particularly strong. Other explanations are that there is a declining trend in gender discrimination, cultural patterns assigning a limited role to women, confining them to household activities, and lower economic returns to labor participation prevailing in the past century.

The second variable most strongly associated with dropouts during the period analyzed is the employment status of the head of household. According to our analysis, an unemployed head of household is associated with a 12percent higher probability of dropping out of USE. This association is maintained at similar levels over a period of nearly 30 years. This might be because USE age coincides with being of legal working age which presumably increases the short-term opportunity cost (not being able to generate income) of staying in the education system.

Figure 3 also shows that in the early 1980s, a number of factors were associated with dropout including having a female headed household and having youth of USE age being head of household. For the coefficient of gender of the head of household, the value decreases steadily over the following decades, reaching levels of about 4 percent. In contrast, the coefficient related to youth of USE age being head of household increases, reaching values of about 10 percent in 2012. The reduction in the value of the first of these two coefficients can be related to increased labor force participation of women in Mexico, since the gap in returns to education between men and women has also been reduced.

The other two features that show statistically significant associations over the three decades under analysis are the employment status of USE age youth and household size. As expected, youth that are working are less likely to attend school. With regard to household size, the positive association between household size and dropout may be due to the fact that the economic needs of the household generally increase as the household size is greater and it is common for both of these responsibilities to fall on the economically active household members, which usually includes youth over of 15 years of age.

The variables that reduce the likelihood of dropout (and which consistently show significant effects) are educational level of the head of household and household income. These associations are not surprising as both are related with greater ability to invest in human capital. Of these two variables, the strongest factor negatively associated with dropping out is a higher household income, which has a coefficient with the most considerable magnitude of all variables incorporated (incomes generated by individuals in the 15-18 age range are not considered in the estimation). Interestingly, in the early 1980s the marginal effect of income on the probability of dropout was nearly 30 percent, and its value systematically decreased during the course of the following decades. Even so, by 2012 the value was still about 15 percent. This result is consistent with the assessment of the ENDEMS that economic resources are strongly associated with dropout.

An alternative estimation is performed by using the 2012 ENIGH data, which incorporates additional variables of interest including the access to the Oportunidades Program and belonging to an indigenous group; these were not included in Figure 3 since they are only available for the recent surveys. Results are presented in Table 2 and show that the gender coefficient is in fact not statistically significant, which is in line with the reversal of the gender gap in USE school attendance discussed above. Interestingly, belonging to a household that is beneficiary of the Oportunidades program appears to have a strong negative and statistically significant effect on the probability of having dropped out from USE at ages 15-18. This is an expected result since Oportunidades influences decisions related to schooling by increasing household income and by establishing attendance as a condition for support. 
TABLE 2: Relationship between USE school dropout at ages 15-18 and individual factors, 2012 (marginal effects from Probit estimation).

\begin{tabular}{lcc}
\hline Independent variable & Coefficient (1) & Coefficient (2) \\
\hline Female & -0.05 & -0.02 \\
Oportunidades beneficiary & $-0.67^{* * *}$ & $-0.56^{* * *}$ \\
Female-Oportunidades interaction & & $-0.12^{* *}$ \\
Indigenous & $0.16^{* *}$ & $0.10^{* *}$ \\
Household per capita income & $-0.21^{* * *}$ & $-0.02^{* * *}$ \\
Value of household assets & $-0.08^{* *}$ & $-0.04^{* *}$ \\
Rural area & $0.12^{* * *}$ & $0.12^{* * *}$ \\
Access to health services & $-0.13^{* *}$ & $-0.28^{* * *}$ \\
Education of household head & -0.02 & $-0.02^{*}$ \\
Education of head's spouse & $-0.04^{* *}$ & $-0.07^{* *}$ \\
Unemployed household head & $0.12^{* *}$ & $0.16^{* * *}$ \\
Household size & $0.02^{*}$ & $0.01^{*}$ \\
No. observations & 1,559 & 1,559 \\
Pseudo $R^{2}$ & 0.23 & 0.23 \\
\hline
\end{tabular}

Source: author's estimations from ENIGH data.

${ }^{*}$ Statistically significant at $90 \%,{ }^{* *}$ statistically significant at $95 \%$.

${ }^{* * *}$ statistically significant at $99 \%$.

In order to explore the connection between dropout and the gender-Oportunidades relationship simultaneously we perform a second estimation including these variables interacted (see the second column of Table 2). The coefficient with the interaction variable is negative and statistically significant, which suggests that the Oportunidades effect on dropout is in fact stronger for females. Alternatively the coefficient can be interpreted as indication that being female can have a significant effect on dropout when the household where the youth belongs is an Oportunidades beneficiary. This result is in line with the findings by Fiszbein and Schady [10] commented above.

Another important result from the first of the two estimations is that speaking an indigenous language is positively associated with dropping out before completion of USE and this association is statistically significant. Another result, aligned with the previous subsection, is that economic factors are also important (e.g., association between level of income and dropping out of school). This estimate further incorporates an index that represents the value of household assets, which also has an important negative association (the greater the value of assets the lower the dropout). We also incorporate the urban or rural location of the household as an indicator that approximates, inter alia, access to basic services in a broader sense. We find that being located in a rural area significantly increases the probability of dropping out before completing USE.

The strength of the association between dropout and access to health services is similar to that observed between drop out and rural location of residence, but in the opposite direction. That is, greater access to such services is associated with a lower likelihood of dropping out. This may be because better health is associated with higher educational achievement and vice versa, but it may also be capturing an additional effect of the correlation between the supply of public services in education and health.

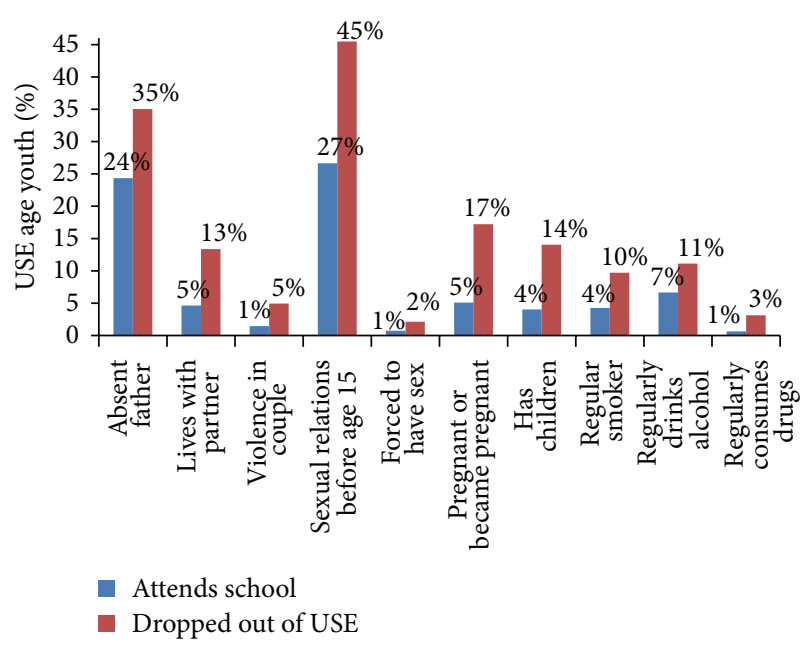

FIGURE 4: Prevalence of risks and addictions in USE age youth in Mexico in 2010. Source: author's calculations from ENJ data, 2010.

As expected, having an unemployed head of household increases the likelihood that a youth of USE age will drop out. In contrast, household size records a less intense association. Finally, higher education levels of both the head of household and his or her spouse have a significant negative effect on dropping out. Our estimates show a stronger association between the education levels of the spouse than with the head of household.

The data from the ENJ complements this analysis by allowing the incorporation of risk-related variables. Figure 4 shows a descriptive comparison as illustration for several dimensions, by comparing the situation of 15-18-year-old youth who attend school versus those who have dropped out. For example, it appears that among youths who have dropped out of school 35 percent live in a household in which the father is absent, while the rate among those who remain in school is 24 percent. According to our results, 13 percent of dropouts aged 15 to 18 live with their partner while only 5 percent of those who remain in school are in this situation. Additionally, 45 percent of those who have left the education system had engaged in sexual activity before age 15 , while the prevalence among those who continue is 27 percent.

There are also important differences between the two groups in terms of the percentage of those who have caused or experienced teen pregnancy (17 percent among dropouts and 5 percent among those who remain in school (teen pregnancy rates are measured over young women in the 15-18 age group.)); the portion of those with children (14 compared to 4 percent); and in terms of the portion of those who smoke and drink alcohol regularly, with a prevalence of more than 10 percent in each of these activities among those who drop out compared to a prevalence of 4 percent and 7 percent, respectively, among those who are still in school. An interesting result is that the percentage who reported having used drugs is three times higher among those who are no longer in USE than among those who continue, although as expected the declared consumption rate is low. 
TABLE 3: Association between having dropped out of school, at ages 15-18 and risk related variables, 2010.

\begin{tabular}{|c|c|}
\hline Independent variable & $\begin{array}{c}\text { National } \\
\text { sample }\end{array}$ \\
\hline \multicolumn{2}{|l|}{ Control variables } \\
\hline Size of household & 0.002 \\
\hline Rural & $0.017^{*}$ \\
\hline Sex & -0.014 \\
\hline Married or cohabiting & 0.031 \\
\hline Medical service & $-0.032^{* *}$ \\
\hline Education household head & $-0.008^{*}$ \\
\hline Education of spouse & $-0.008^{* *}$ \\
\hline Head speaks indigenous language & $0.014^{* *}$ \\
\hline Head unemployed & $0.003^{* *}$ \\
\hline Index of assets & $-0.008^{*}$ \\
\hline Oportunidades scholarship & $-0.005^{*}$ \\
\hline \multicolumn{2}{|l|}{ Risk-related variables } \\
\hline Absent parent & 0.020 \\
\hline Lives with partner & 0.017 \\
\hline Has experienced violence from partner & 0.039 \\
\hline Had sex before age 15 & $0.019^{*}$ \\
\hline Has been forced to have sex & -0.003 \\
\hline Has been pregnant or gotten someone pregnant & $0.040^{*}$ \\
\hline Number of children born & 0.010 \\
\hline Smokes cigarettes regularly & $0.012^{*}$ \\
\hline Drinking alcohol regularly & $0.022^{* *}$ \\
\hline Uses drug regularly & $0.096^{* * *}$ \\
\hline
\end{tabular}

Source: own estimations from the National Youth Survey (ENJ) for 2010. $*, * *$, and $* * *$ represent statistical significance at $10 \%, 5 \%$, and $1 \%$, respectively.

In order to identify more precisely the association between dropping out (when of USE age) and the risk factors included in the ENJ we estimate a Probit model where the dependent variable is a dummy indicating if the individual attends school, and as independent variables we consider a set of control variables, and each of the individual risks for which the survey provides information. Table 3 presents our results.

One key finding from this analysis is that, although the magnitude of the coefficients varies, we obtain generally similar results in terms of sign and significance for a number of indicators (e.g., household location, access to health services, education of the household head and spouse, speaking an indigenous language, the household asset index-in this case the income variable is not included as it is incomplete in the ENJ-and participation in the Oportunidades Program) and their association with dropping out as in Figure 3.

In addition to these variables, we also explored the association with risk indicators. While it is not possible to determine the directionality, our analysis finds that there is a positive and statistically significant association between dropping out and having engaged in sexual activity before age 15 , having been involved in teen pregnancy, smoking, drinking alcohol, and using drugs regularly (it is important to note that the marginal effects shown in Table 3 cannot be interpreted as a causal link, since it is possible that risk behaviors are causing dropout, but it is also possible that dropping out of the education system is the motive for such behavior. Since we do not have further information to determine the directionality, for our purposes we simply conclude that the significant association exists).

In sum, although we cannot always establish the direction or consequences of causality between variables representing personal and family risk situations and behaviors and dropout rates, one can say that there is a close and important relationship that must be taken into account to better understand the reasons for dropout during USE.

4.2. Community Factors. In the previous sections we focused on analyzing databases that contain information about specific individuals which may be associated with a set of indicators that reflect their personal characteristics, their families, access to services, and even some prevailing risk behaviors at the individual level. To explore the relationship between community factors and dropout we turn to a different approach and data source to incorporate information about the environment and the local context.

Specifically, to expand the data base for analysis and guarantee greater representation of different environments, we add information at the municipal level. To characterize the magnitude of dropouts in each municipality we access the microdata from the 2010 National Population and Housing Census which specifies for each individual of school age whether or not they attend school. With this information we calculate municipal dropout rates for youth between ages 15 and 18, and we link it to a set of variables that are representative of the conditions prevailing in the same municipality.

A variable of particular interest incorporated in this analysis is the quality of education. This is measured by the percentage of students in each municipality that have reached a "good" or "excellent" level attainment in the areas of math and communications, measured by the 2013 USE ENLACE test (ENLACE is the national standardized test applied to all schools in the last year of USE and which measures the level of competencies developed in communications and mathematics skills). The argument is that dropout rates of students at the municipal level are influenced by a variety of factors, and they respond to the quality of educational services. We were not able to consider other potentially good measures of quality such as the number of pupils per teacher, or the level of teacher qualifications, since the data is not available at the municipality level as our approach requests.

For introducing complementary variables to characterize additional elements of the context of each municipality, we use information in the Statistical Information Bank of INEGI, which contains data on the social, economic, and contextual conditions, which can then be studied in terms of their relation to dropout rates.

For the characterization of socioeconomic levels we use four measures: the percentage of households benefiting from 
TABLE 4

\begin{tabular}{|c|c|c|c|c|c|}
\hline Independent variable & $\begin{array}{c}\text { Robust standard } \\
\text { errors }\end{array}$ & $\begin{array}{l}\text { Estimate } \\
\text { VCE }\end{array}$ & $\begin{array}{l}\text { Weighted } \\
\text { OLS }\end{array}$ & $\begin{array}{c}\text { Instrumental } \\
\text { variables (IV) }\end{array}$ & $\begin{array}{l}\text { IV with control } \\
\text { for migration }\end{array}$ \\
\hline Results ENLACE USE & $-0.036^{*}$ & $-0.036^{*}$ & $-0.041^{* *}$ & & \\
\hline Instrumented ENLACE USE & & & & $-0.053^{* *}$ & $-0.043^{*}$ \\
\hline$\%$ in Oportunidades & $-0.082^{* * *}$ & $-0.082^{* *}$ & $-0.081^{* * *}$ & $-0.076^{* *}$ & $-0.064^{*}$ \\
\hline$\%$ houses with dirt floors & -0.001 & -0.001 & -0.003 & 0.007 & $0.011^{* *}$ \\
\hline Rate rurality & $0.052^{* * *}$ & $0.052^{* * *}$ & $0.057^{* * *}$ & $0.065^{* * *}$ & $0.046^{* *}$ \\
\hline Infant mortality rate & $0.151^{*}$ & 0.151 & 0.098 & $0.176^{*}$ & $0.162^{* *}$ \\
\hline Unemployment rate & $0.292^{* * *}$ & $0.292^{* * *}$ & $0.206^{* *}$ & $0.345^{* * *}$ & $0.351^{*}$ \\
\hline$\%$ with electricity/water & $-0.222^{* * *}$ & $-0.222^{* * *}$ & $-0.215^{* * *}$ & $-0.327^{* * *}$ & $-0.301^{* *}$ \\
\hline$\%$ international migration & & & & & 0.028 \\
\hline Constant & -0175 & -0175 & -0.160 & -0.198 & -0.144 \\
\hline$R^{2}$ & 0.347 & 0.223 & 0.228 & 0.324 & 0.328 \\
\hline No. Obs. & 2,456 & 2,456 & 2,456 & 2,456 & 2,456 \\
\hline
\end{tabular}

${ }^{*}$ Statistically representative at 10 per cent level; ${ }^{* *}$ statistically representative at 5 per cent level; ${ }^{* * *}$ statistically representative at 1 per cent level.

the Oportunidades and Food Aid Programs, the percentage of households with dirt floors, the percentage of communities in the municipality with fewer than 5,000 inhabitants (which is commonly used as a measure of rurality), and the infant mortality rate. These provide information about the number of households in poverty and about their health conditions. To characterize the economic environment, and in particular, the dynamics of the labor market, we include the percentage of the economically active population that is unemployed. We also consider the percentage of households with electricity and running water as a representation of access to public services.

Table 4 presents a summary of our estimates (we estimate the model with different econometric methods to address various potential biases. To address heteroskedasticity problems commonly found in such regressions we estimate robust standard errors and weighted least squares. We find that the estimated standard errors using robust results generate more efficient estimators, so we use this procedure to corroborate our estimates and if the results are robust to other types of methodological approaches). Through the estimation with robust standard errors we find that the higher educational quality, as measured by the results of ENLACE, the lower the dropout observed in the Municipality. When estimating the model with robust standard errors and by weighted least squares, respectively, we obtain the same conclusion, although in the case of the latter method, the association has a higher level of statistical significance. It should be mentioned, however, that these cannot be interpreted directly as evidence of causality - that a cause of dropout is low quality-since it is possible that those who dropped out from the education system have a specific academic profile that might affect the ENLACE results. For instance, if those dropping out have lower academic achievement, the ENLACE results will be upward biased, and vice versa.

To address this issue, we also include an estimation by instrumenting the ENLACE score with its lagged value in the previous year, by municipality. This is an adequate instrument since the results are from a different cohort that left the schooling system before the current cohort under consideration in the dependent variable. In this case also, the coefficient for the ENLACE variable is negative and statistically significant, which confirms the previous regression results.

Another important issue to be considered is migration, since ENLACE scores might be biased by differential rates of youth moving to other geographic areas. For instance, if youth with better academic performance migrate out of the country, the scores will be underestimated to a larger extent in the municipalities with greater population expulsion, and vice versa. Furthermore, migration might also affect the estimated dropout rate in a similar way in the independent variable.

Fortunately, the Sample of the 2010 Population Census by INEGI includes some information that allows computing a measure of international migration at the municipality level which we can include in our estimations (specifically, the Census asks each household for the number of household members that have emigrated to another country, as well as their age. With this data we add the number of migrants in the 15-18 age group to the current USE age population registered in the municipality and simply calculate the share of migrants in the total population age group. The questionnaire, however, only asks about international migration so we are not able to consider national migration across municipalities). So, Table 4 includes an additional regression where apart from instrumenting the ENLACE test scores as before, we include the share of international migration by municipality as independent variable in the regression. As can be seen, in general the main result of the relation between dropout and education quality holds, although the coefficient losses significance slightly. The coefficient for the variable measuring the level of international migration is positive, but not significant. This suggests that either there is not a generalized educational profile for migrants across the country or that those migrating do not alter on average the educational outcomes in the municipalities at the national level. 
Table 4 also presents the coefficients of the variables that characterize the socioeconomic environment. In this case it is observed that higher percentages of households benefiting from the Oportunidades are associated with lower school dropout in all cases. As would be expected, the coefficient of the association between the share of rural population and the rate of dropout is positive and statistically significant. In the case of the infant mortality rate the sign is also positive, and statistically significant in most cases, including the last two regressions which would be the preferred estimates.

Another interesting result is that the higher the unemployment rate in the municipality, the higher the dropout rate, although the result cannot be interpreted as evidence of causality between variables in a specific direction, because on one hand it is possible that the higher unemployment increases pressure on the use of time for youth of USE age, who may find it necessary to leave school to generate income for the household, and on the other hand, the higher dropout may correspond to more youth seeking employment in the same community, which may restrict options in the labor market, with the consequence of higher unemployment. The association is maintained in the three estimates. We also find that with increased access to electricity and water there is lower dropout.

In sum, these results suggest that in addition to the personal and household characteristics, and the previously documented social risks, community and social contexts in which individuals live are also closely related to retention in education at the typical age of upper secondary attendance. Of particular interest is the association with academic achievement as measured by ENLACE, as this is a factor directly related to educational policy.

4.3. Macroaggregate Factors. The third group of variables that we would expect to have an impact on dropout decisions encompasses those that deal with the environment more broadly, covering not only the community but also the more general context.

To analyze the relationship we build a database with information at the state level to see if there is an identifiable relationship between dropout levels in each state and elements of the general environment, with an emphasis on the economic conditions that may influence the demand for educational services. Unlike for the analysis of community factors, we include observations over time to form a balanced panel that includes the 32 states of the country over a span of 23 years between 1990 and 2012 .

One factor of particular interest at this level, and that has not been explored yet in our analysis, is the influence of the returns to education on dropout. Since one of the purposes of schooling is to generate better income opportunities, it would be expected that with greater returns to education there would be a higher opportunity cost of dropping out, and therefore, fewer youth would exit the education system before graduating from USE. Although our focus is on USE, in addition to verifying the relationship with the returns to this level, it is also of interest to identify the relationship with the returns to higher education because USE is a prelude to

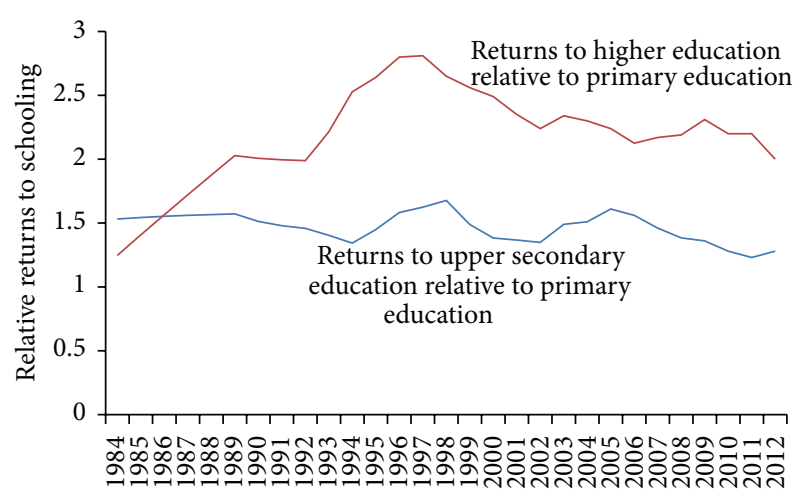

FIGURE 5: Estimated returns to education in Mexico 1992-2012. Source: author's calculations from the National Employment Survey.

this educational level. With greater returns to HE, we would expect fewer dropouts at the USE level.

To verify the statistic association with dropout we construct a panel with data at the State level for 1990-2012, where education returns (a matrix of 32 States by 22 years) are estimated from data from the National Occupation and Employment Surveys (ENOE), which as opposed to the ENIGH are representative at the State level throughout. We link the panel of data to the state dropout rates in USE, which we define as the dependent variable.

The evolution of the average relative returns across states by year is presented in Figure 5. (the estimates are from standard Mincer specifications controlling for selection bias. The results and in particular the value of the $\lambda$ coefficient for the estimation of returns in every State and year are available from the authors. With very few exceptions the coefficient is significant, and, thus, the selection bias correction is correct. It should be mentioned, however, that the returns might still be biased to some extent by differential migration across education groups. Depending on the level of income by education level obtained by those that migrated, the actual differentials might vary. For instance, if a larger proportion of individuals that only have primary education migrate to the United States and obtain higher wages there, the returns to higher education relative to primary schooling in Figure 5 for Mexican nationals (regardless of their current location) will be overstated, and vice versa). Interestingly, the returns to HE relative to primary show an inverted " $\mathrm{u}$ " shape trend, while the returns to USE relative to primary are relatively more stable, although with a similar reduction since the mid2000s years. Both trends are consistent with increased drop out from USE.

As in Sections 4.1 and 4.2, the selection of additional information for the estimation is a function of the availability of state-level data for a sufficient period of time. The Information Bank of INEGI includes state data for some variables including the state's Gross Domestic Product (GDP) which can be used to control for the level of overall development of the state, the rate of employment in the informal sector (which is presumably a reflection of employment conditions that prevail locally), and the female labor market participation rate, which is a good indicator of the opportunities that 
TABLE 5: Estimated association between macroaggregate factors and dropout rates with fixed effects.

\begin{tabular}{lc}
\hline Independent & National \\
variable & sample \\
\hline Returns to higher Ed & $-10.04^{* * *}$ \\
Returns to USE & $-5.89^{* * *}$ \\
Returns to secondary Ed & $-7.27^{* * *}$ \\
Ln GDP per capita & $-34.25^{* * *}$ \\
\% informal employment & $0.005^{* * *}$ \\
\% female labor participation & $0.25^{*}$ \\
Teachers for USE campus & $-0.445^{* *}$ \\
\% of 15-18 year olds that migrate & 1.876 \\
Constant & -332.01 \\
No. observations & 736 \\
\hline
\end{tabular}

Source: own calculations. $*, * *$, and $* * *$ indicate that the effect is statistically significant at $10 \%, 5 \%$, and $1 \%$, respectively.

are accessible to women. Additionally, in order to incorporate information on the supply of USE educational services, we calculate the number of teachers per USE school by state from the 2012 SEP data, and we include a control variable representing the proportion of 15-18 year olds that migrate internationally as in the previous section.

Fixed and random effects methods were used for the panel estimation, and in all cases the Hausman test indicates that the fixed effects model is more consistent and is preferred, so these are the ones we present here. Thus, although the number of independent variables considered is small, the results control for time invariant state characteristics.

The results are presented in Table 5. The first set of coefficients quantifies the strength of the association between USE dropout at the state level and returns to education. We find that the relationship between the returns to secondary education, USE, and higher education and dropouts is negative; that is, the higher the returns, the lower the dropout rates. This is consistent with the hypothesis that the returns increase the cost of leaving the educational system.

We find some additional interesting differences. The first is that the magnitude of the effects for higher education is greater than for USE and secondary education, which suggests that the role of USE as a platform for access to higher education is more important in these cases. However, as previously, we interpret the coefficients only as associations between variables because the returns on the one hand can determine the decision to stay or not in the education system, but on the other, they are also determined by the supply of human resources, which is a function of school attendance.

Two other consistent results are that the state dropout rate is inversely related to income levels-in states with a higher GDP per capita there is less dropout-and is directly related to the rate of informal employment-with more informality there is more dropout. One interpretation of the latter result is that if the labor market does not offer employment opportunities with benefits and other desirable elements, there are fewer incentives to continue to invest in education and finish USE. The coefficient for the migration variable, however, is not significant.

\section{Conclusions}

The objectives of this study are to characterize the phenomenon of dropout in Mexico, understand its implications, and identify to the extent possible its causes.

According to our results, the consequences of dropping out are many, ranging from the most apparent, which is the inability to pursue higher education (which has the highest economic returns) to reduced opportunities for securing employment, access to lower wages, and higher levels of informality. One dimension explored is that the prevalence of social risks observed for those that dropped out from USE and are observed later between 19 and 24 years includes early pregnancy, and the propensity to addiction, which can have long-term effects with multiple impacts, including intergenerational effects.

As for explanations, we combine different databases and statistical methods ranging from the use of surveys with information on specific individuals to data aggregated at the municipal and state level to explore the importance of the relationship between dropout rates and family, personal and economic factors, community and social factors, and macroaggregated factors.

The factors at the individual-family level identified with USE drop out in the long run include mainly gender (which was the most relevant factor during the 1980s but has lost its significance over the years), having a head of household unemployed, becoming a household head, low household income, living in rural areas, large household size, and low levels of education of the household head and spouse. An analysis performed for the year 2012 using a larger number of variables also reveals that belonging to an indigenous group significantly increases the probability of dropout, while belonging to a household that is beneficiary of the Oportunidades program significantly reduces the probability of dropout. Interestingly, this last effect is stronger in the case of women, which is consistent with the fact that these types of conditional cash transfer programs include larger scholarships for females.

As for the community and macrofactors, the main conclusions are that we find evidence of a strong association between low school quality and dropout and that higher returns to USE and higher education are related to lower USE dropout.

In sum, there are multiple relevant elements that form a complex and multifaceted panorama. This implies that addressing the problem requires different policy instruments and different approaches.

\section{Conflict of Interests}

The authors declare that there is no conflict of interests regarding the publication of this paper. The authors are at the World Bank and at the Center for Education and Social Studies, respectively. 


\section{Acknowledgments}

The authors thank the helpful comments and suggestions by an anonymous referee, which helped improve the paper substantially. They would also like to thank the collaboration by Jonathan Karver, Pamela Mendoza, and Melissa Merchant.

\section{References}

[1] OECD, The High Cost of Low Education Performance, Organization for Economic Co-Operation and Development, Paris, France, 2010.

[2] R. Castañón and R. M. Seco, La Educación Media Superior en México, Noriega Editores, Mexico City, Mexico, 2000.

[3] S. Didou and S. Martínez, Evaluación de las Políticas de Educación Media Superior y Superior en el Sector Tecnológico Federal, Subsecretaría de Educación e Investigación Tecnológicas, Secretaría de Educación Pública, Mexico City, Mexico, 2000.

[4] J. F. Zorrilla, El Bachillerato Mexicano: un sistema académicamente precario, Instituto de Investigaciones sobre la Universidad y la Educación, Universidad Nacional Autónoma de México, Mexico City, Mexico, 2008.

[5] J. F. Zorrilla, T. Bracho, F. Miranda, and F. Martínez, La Educación Media Superior en México: Balance y Perspectivas, Secretaría de Educación Pública, Mexico City, Mexico, 2012.

[6] F. Solana, R. C. Reyes, and R. Bolaños, Historia de la Educación Pública en México, Fondo de Cultura Económica, México City, Mexico, 2000.

[7] A. Arredondo, Entre la Primaria y la Universidad; la Educación de la Juventud en la Historia de México, Santillana, Mexico City, Mexico, 2008.

[8] SEP, Sistema Nacional de Información Educativa, Secretaría de Educación Pública, Mexico City, Mexico, 2012, http://www.snie .sep.gob.mx.

[9] W. Cunningham, L. McGinnis, C. García-Verdú, C. Tesliuc, and D. Verner, Youth at Risk in Latin America and the Caribbean, The World Bank, Washington, DC, USA, 2008.

[10] A. Fiszbein and N. Schady, Conditional Cash Transfers: Reducing Present and Future Poverty, World Bank, Washington, DC, USA, 2009. 

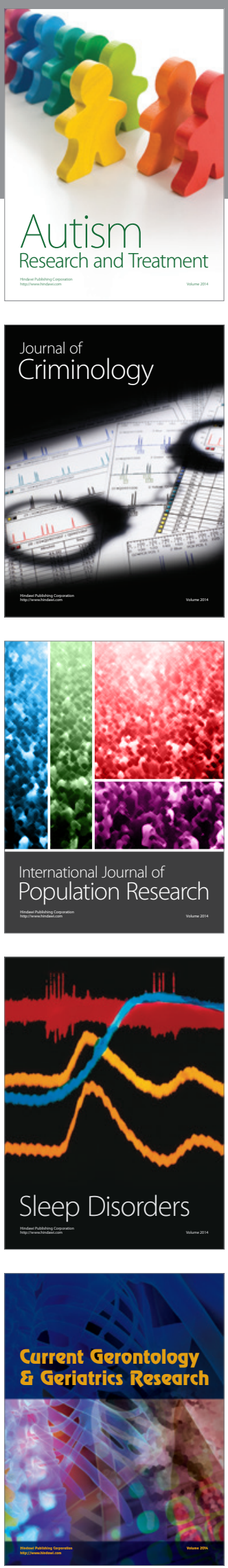
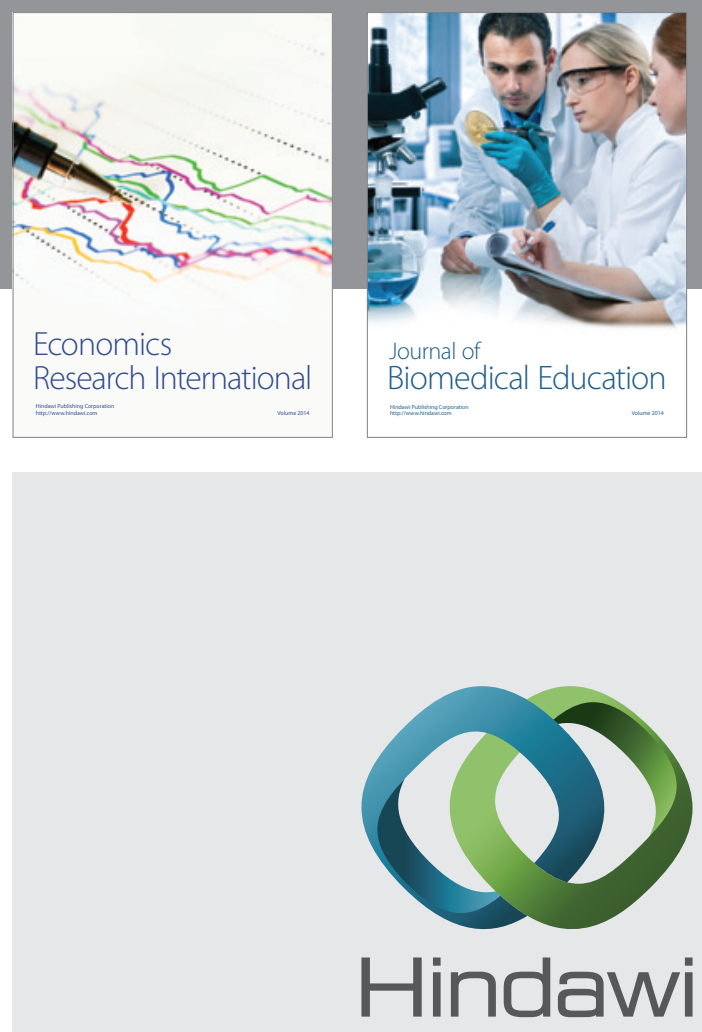

Submit your manuscripts at

http://www.hindawi.com
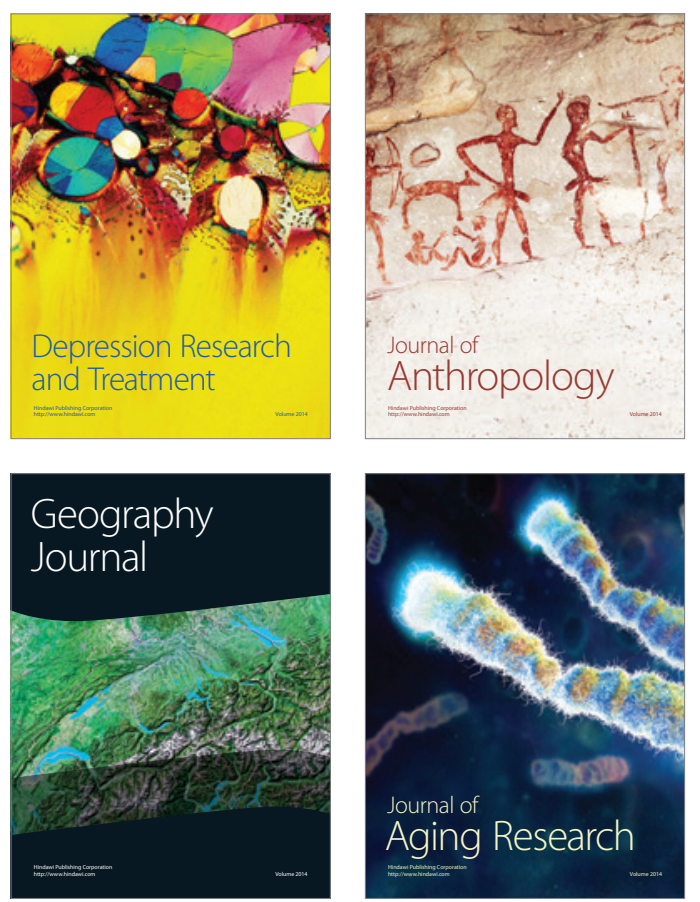
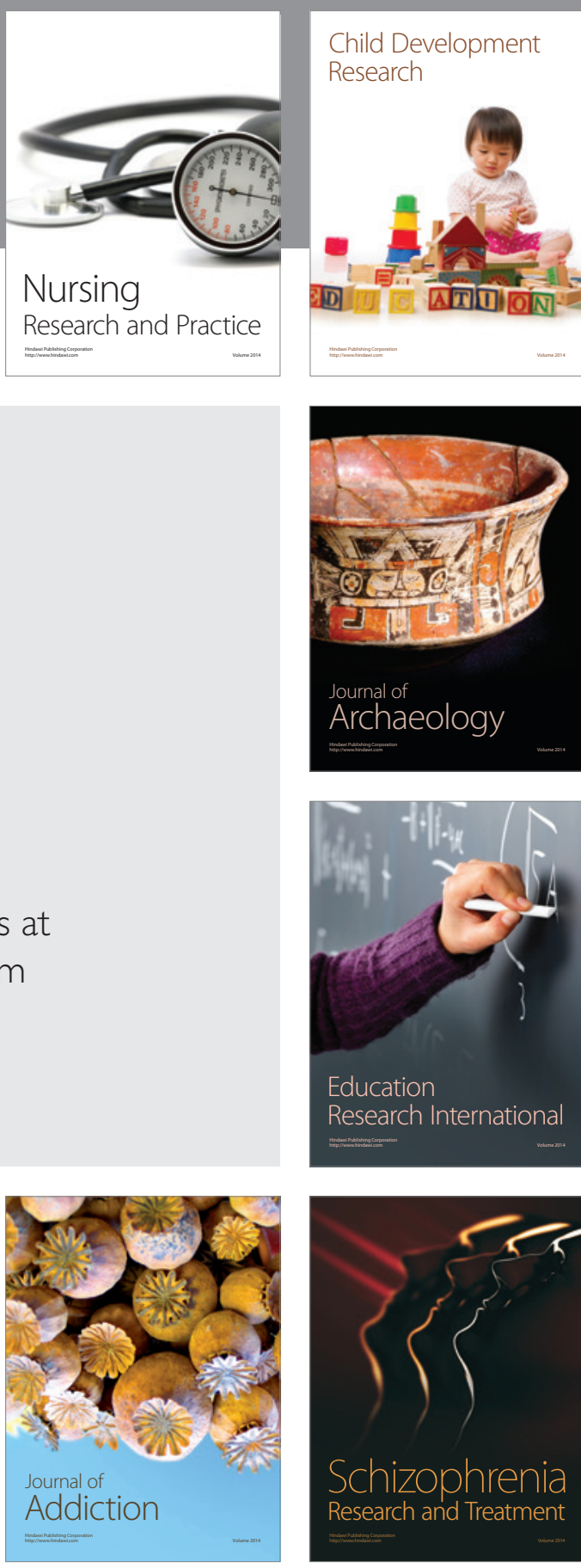

(D)
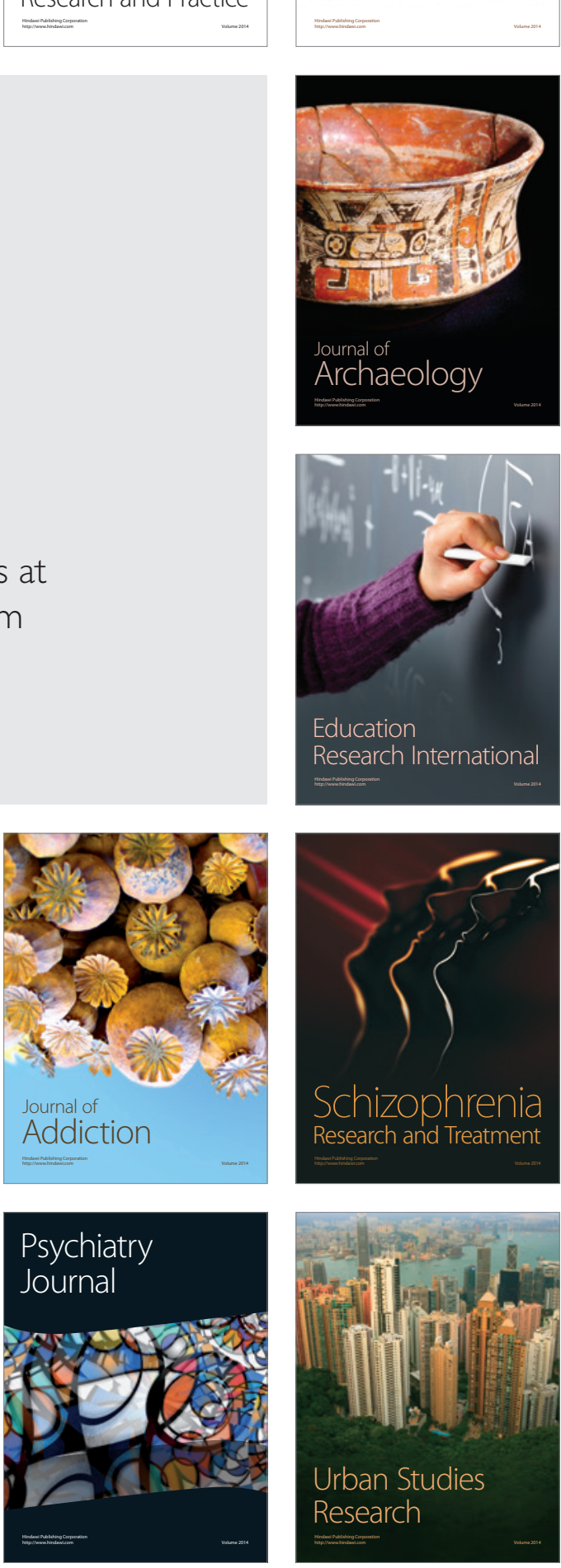